\title{
Numerical analysis of ground motion in a South African mine using SPECFEM3D
}

\author{
X Wang Laurentian University, Canada \\ M Cai Laurentian University, Canada
}

\begin{abstract}
Intensive seismicity was often observed in the front of tabular stopes in South African gold mines. The seismicity was usually caused by high stress concentration due to excavation, and some of the seismic events were fault rupture events. This study focuses on numerical modelling of seismic wave propagation resulted from a moment magnitude $M w=1.4$ seismic event occurring on 9 July 1996 at Mponeng mine in South Africa, using an advanced numerical tool called SPECFEM3D. Both point and non-point source models are considered and ground motions along a haulage tunnel at a depth of 2,650 $\mathrm{m}$ are analysed and compared with field monitoring data. It is found that the non-point source model produces better results than the point source model in near-source field. The haulage tunnel and the mined-out areas have a large influence on the ground motions. In the modelling results, strong ground motion localisation is observed at certain areas of the haulage tunnel and in the mined-out areas. Most of the simulated seismograms agree with the field recorded ones. It is seen that SPECFEM3D is a useful tool for modelling seismic wave propagation in underground mines.
\end{abstract}

Keywords: ground motion modelling, seismic wave propagation, source models, SPECFEM3D

\section{Introduction}

Many scientific studies have been conducted in South African gold mines to understand seismicity in front of tabular stopes (i.e. McGarr 1971; McGarr et al. 1975, 1979). Many small seismic events and tremors were caused by high stress concentrations due to excavation (McGarr 1971; McGarr et al. 1975). Dense seismic networks were installed in the inferred seismogenic areas in advance of the stope excavation to observe seismic events (Yamada et al. 2005, 2007). It has been concluded that most large seismic events in the gold mines were the results of shear failure of rock, which was similar to natural earthquakes in terms of mechanism and source parameters (i.e. Spottiswoode \& McGarr 1975; McGarr et al. 1979; McGarr 1994; Richardson \& Jordan 2002).

Mponeng mine is a gold mine in South Africa's North West Province, and it is one of the deepest underground gold mines in the world. Several studies have been conducted at this mine to address mine seismicity and rockburst problems (Yamada et al. 2005, 2007; Kwiatek et al. 2011). Figure 1 shows the mining layout at a depth of $2,650 \mathrm{~m}$ and a research area, denoted by different colours. Nine triaxial borehole accelerometers (green triangles) were installed within a range of $200 \mathrm{~m}$ along a haulage tunnel (Ogasawara \& The Research Group for Semi-controlled Earthquake-generation Experiments in South African Deep Gold Mines 2002; Yamada et al. 2005). Five mining-induced seismic events (red circles) were observed during the mining period from February to October 1996.

In this paper, seismic event \#1 (occurred on 9 July 1996) with a moment magnitude of Mw = 1.4 was selected to conduct a case study. This seismic event was considered a fault rupture event. Yamada et al. (2005) estimated from their study that the rupture speed was about 2,500 m/s (which represents $65 \%$ of the shear wave velocity of the rock). After a series of inverse analyses, they found that the dynamic rupture process of the event and other nearby events were similar to that of large natural earthquakes. 


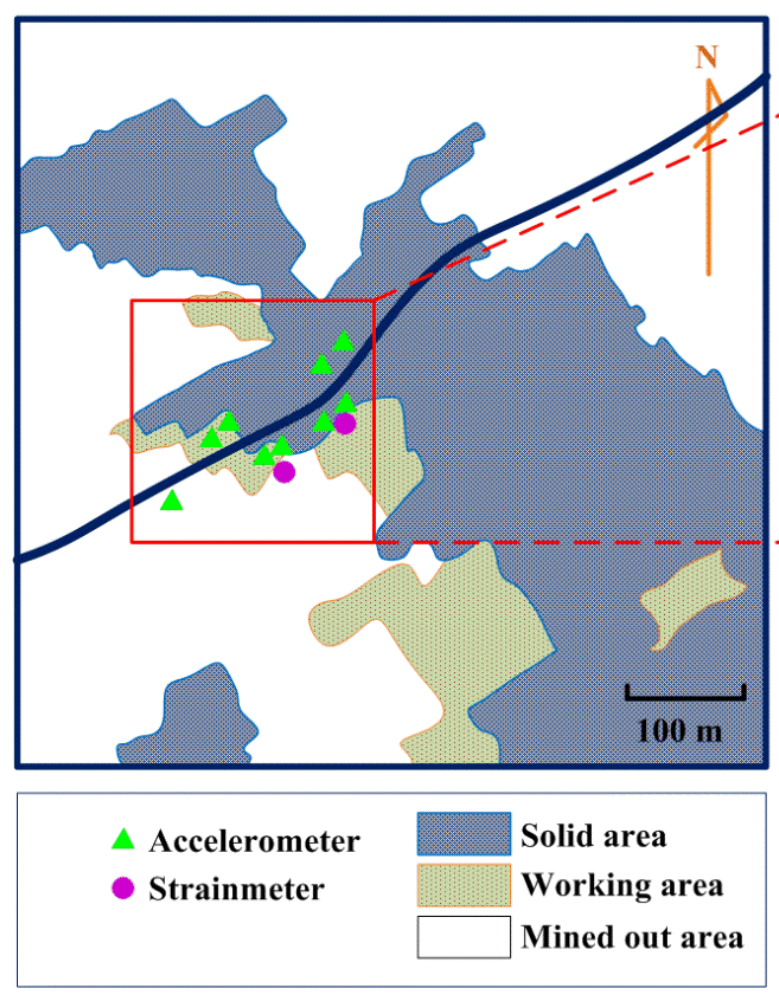

(a)

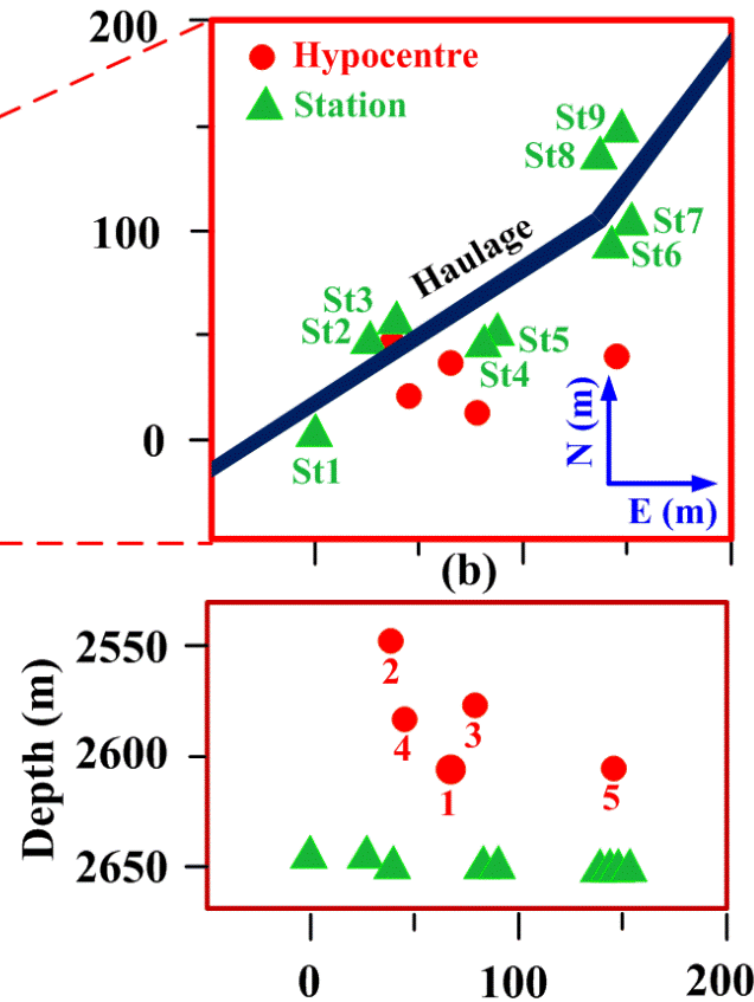

(c)

Figure 1 (a) Receiver stations and mining layout. Blue/green/white areas stand for solid gold reef/working/mined-out areas from mining activities from February to October 1996, respectively. The haulage tunnel is denoted by the dark blue line. Accelerometers and strainmeters are denoted by the green triangles and pink circles, respectively; (b) An enlarged map view that highlights the research area and nine receivers (denoted by green triangles in the east-north cross-section); (c) Receiver locations (green triangles) and derived five hypocentres (red circles) of the seismic events, projected in the vertical cross-section that passes through the tunnel axis. (east, north) $=(0,0)$ corresponds to the St1 (Receiver 1) location (after Yamada et al. 2005)

A research area of $200 \times 200 \mathrm{~m}$ (Figure 1(b)), which included seismic event \#1 (Figure 1(c)), was chosen to conduct this case study. More details about this seismic event are discussed in Section 3. Figure 2 illustrates the configuration of the study area, which consists of the gold reef, the host rock, open stopes, and the haulage tunnel. The rock types above and below the reef were basalt and quartzite, respectively. The gold reef thickness was 0.2 to $0.3 \mathrm{~m}$, dipping $20^{\circ}$ towards the southeast. The open stopes (height $1 \mathrm{~m}$ ) were about $50 \mathrm{~m}$ above the haulage tunnel, which had a width of $5 \mathrm{~m}$. Accelerometers (green triangles) were installed at a depth of $15 \mathrm{~m}$ from the collars in sub-horizontal boreholes to avoid the influence of the tunnel on seismograms.

During the mining period from February to October 1996, more than 25,000 seismic events were recorded. The recorded waveform data had very high signal-to-noise ratios and the wave amplitudes were low in the tail portion of the recorded waveforms at all the receivers, which suggested that the medium in this study area was relatively homogeneous (Yamada et al. 2007). In addition, Ogasawara and The Research Group for Semi-controlled Earthquake-generation Experiments in South African Deep Gold Mines (2002) investigated the site effect and concluded that there was no large site effect because there were no faults, dykes, and other major geological structures in and around this observation area. The field data collected in this study area was used for this case study. 


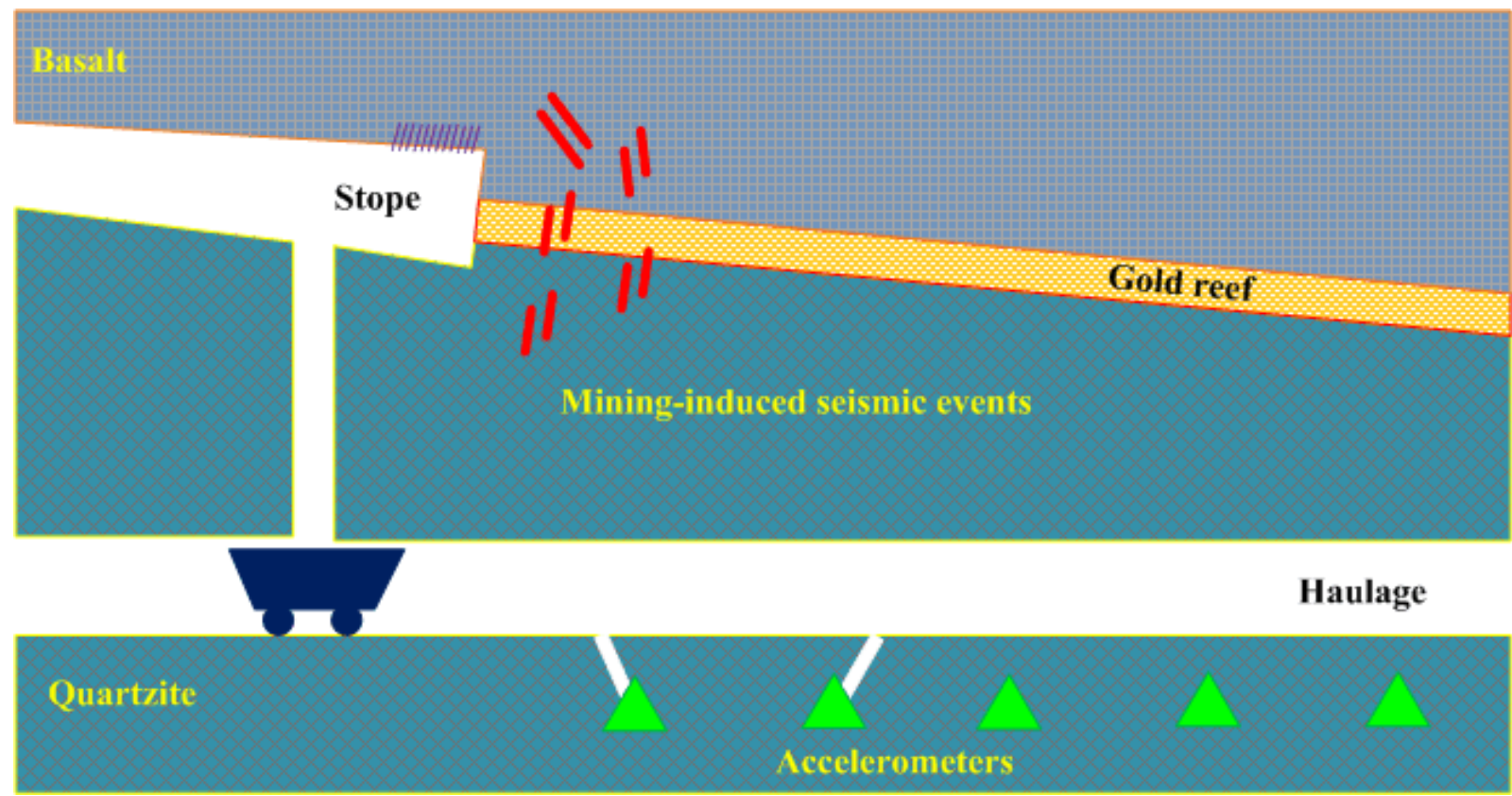

Figure 2 Schematic view of the observation system at Mponeng mine. Accelerometers (green triangles) were installed in the walls using $15 \mathrm{~m}$ long sub-horizontal boreholes. The width of the haulage tunnel was $5 \mathrm{~m}$. The gold reef width ranged from 0.2 to $0.3 \mathrm{~m}$ and the height of the stope was about $1 \mathrm{~m}$. There were no faults and dykes causing offsets of the reef and the stope in and around the observation area (modified from Yamada et al. 2005)

\section{$2 \quad$ Model set-up}

SPECFEM2D and SPECFEM3D are powerful software for seismic wave propagation modelling at local, regional, and global scales, and it is particularly well-suited for handing complex geometries and interfaces (Komatitsch \& Tromp 1999; Komatitsch et al. 2000; Computational Infrastructure for Geodynamics 2012, 2014). Studies on using SPECFEM2D for wave propagation simulation in underground mines have been presented by Wang and Cai (2014, 2015, 2016), Cai and Wang (2015). However, for many mining applications, modelling using SPECFEM3D is needed. SPECFEM3D does not have a good pre-processor to create high-quality hexahedral meshes. For successful application of SPECFEM3D to wave simulation, an external mesh generation tool was used to generate high-quality hexahedral meshes for complex geometries. Normally, a complex model (especially the mined-out stope and the gold reef area) is decomposed into many meshable sub-volumes.

Based on the geometry provided in Figures 1 and 2, a 3D model was constructed and the mesh is shown in Figure 3. The model size was $200 \times 200 \times 150 \mathrm{~m}$, and the volume was divided into 311 sub-volumes that could be properly meshed. The model was meshed with an average element size of $2 \mathrm{~m}$ along the haulage tunnel, $0.5 \mathrm{~m}$ for the orebody (the thickness of gold reef was simplified to $0.5 \mathrm{~m}$ ), and $3 \mathrm{~m}$ for other rocks. The mesh was refined near the tunnel (Figure 3). As a result, this model contained 524,938 spectral elements and 544,483 nodes. The entire mesh was partitioned into 12 sub-domains for parallel computation using 12 CPUs and two GPUs.

Table lists the material properties. $\rho, v, V_{p}$, and $V_{s}$ are rock density, Poisson's ratio, and $\mathrm{P}$ and S-wave velocities, respectively. Air properties were assigned to tunnel and mined-out areas. The parameters were estimated from field observation and laboratory test data. Figure 4 presents the shear velocity model and the layout of receivers in the 3D model. Nine receivers were placed along the haulage tunnel, as shown in Figures 4 and 1, to compare the synthetic seismograms with the recorded waveforms. Attenuation was not considered in order to reduce computation time because of the large number of elements in the model. 


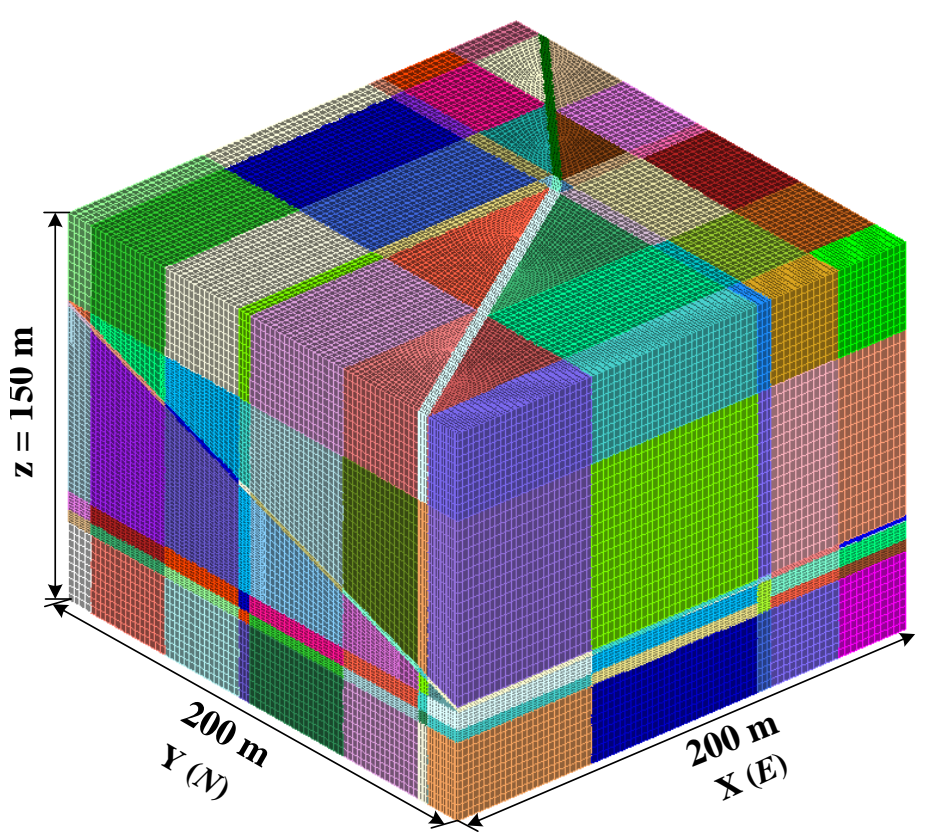

(a)

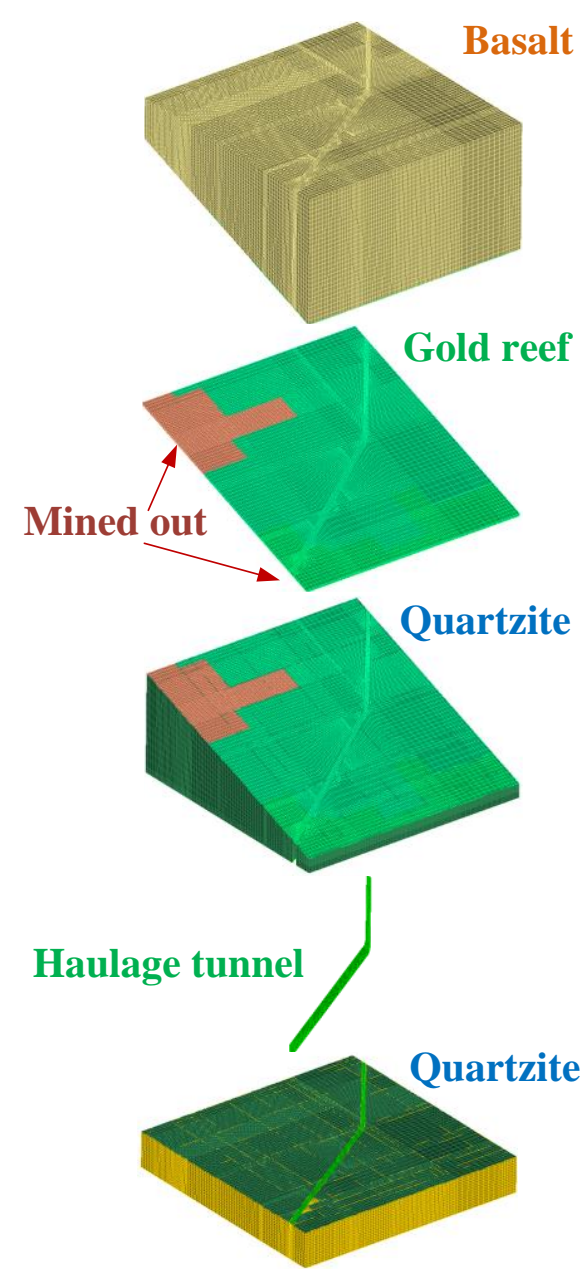

(b)

Figure 3 (a) Spectral-element mesh of the model, which was decomposed to 311 meshable volumes; (b) Perspective view of the main rock domains and structures (basalt, gold reef, quartzite, mined-out area, and haulage tunnel) in the spectral-element mesh, which were combined to form a single body mesh

Table 1 Model material properties

\begin{tabular}{lllll}
\hline Variable name & $\rho\left(\mathrm{Kg} / \mathrm{m}^{3}\right)$ & $v$ & $\boldsymbol{V}_{\boldsymbol{p}}(\mathrm{m} / \mathrm{s})$ & $\boldsymbol{V}_{\boldsymbol{s}}(\mathrm{m} / \mathrm{s})$ \\
\hline Basalt & 2,740 & 0.24 & 6,200 & 4,000 \\
Gold reef & 2,850 & 0.22 & 6,500 & 4,200 \\
Mined out & 1 & N/A & 340 & 0 \\
Quartzite & 2,680 & 0.26 & 6,000 & 3,800 \\
Haulage tunnel & 1 & N/A & 340 & 0 \\
\hline
\end{tabular}




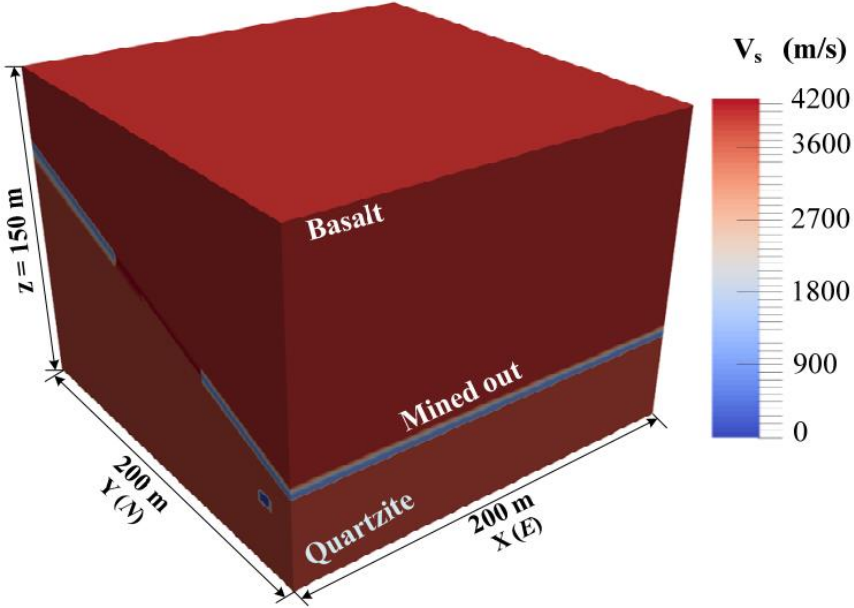

(a)

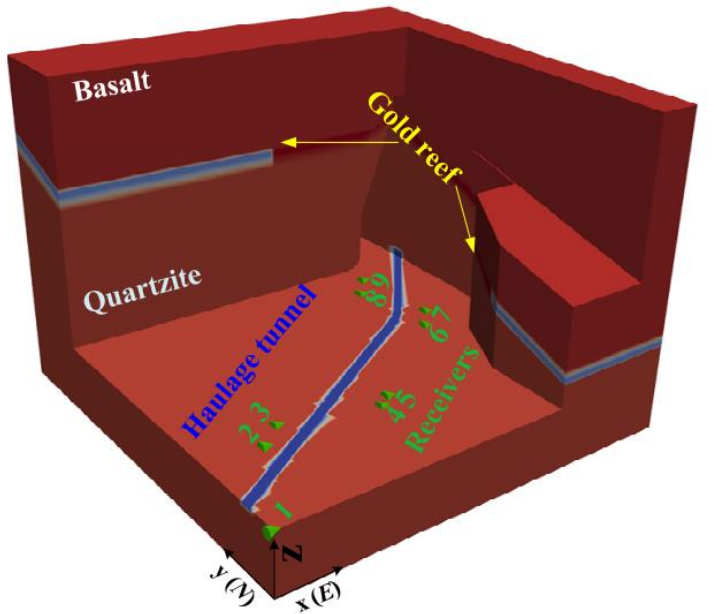

(b)

Figure 4 (a) Shear wave velocity model for various computation domains. Shear wave velocities are represented by the colour scale; (b) Receivers for synthetic seismogram calculation are denoted by green triangles and are numbered from 1 to 9

\section{Seismic source representation}

In general, a moment tensor point source model is used to represent far field fault slip seismic event. In this case study, however, a point source representation to represent a seismic event that is too close to the receivers may not be appropriate and a non-point source model is required for near field seismic sources. In this case, the seismogenic area was only $50 \mathrm{~m}$ above the tunnel and the receivers. Near field seismic source representation therefore holds the key to obtaining a good understanding of the near field source seismic response. Kinematic (dislocation model) and dynamic (crack model) fault source models are two non-point source models. Both the moment tensor and the finite kinematic source models are investigated to provide a preliminary insight of the influence of the seismic source model on seismic response.

The overburden stress was about $70 \mathrm{MPa}$ in this study area and stress concentration due to stope excavation usually causes seismic events in the mining front of the stopes, as shown in Figure 2. As stated, those seismic events were the result of shear failure of rock (McGarr 1971) and were similar to natural earthquakes in terms of source mechanism and parameters (Spottiswoode \& McGarr 1975; McGarr 1994). Considering the quality of the recorded waveforms and the derived normal fault slip mechanism from Yamada et al. (2005), seismic event \#1 (Figure 1 (c)) was selected for this case study.

The event occurred on 9 July 1996 and had a moment magnitude of $M_{\mathrm{w}}=1.4$. Its hypocentre was derived at east $=62.7 \mathrm{~m}$, north $=39.0 \mathrm{~m}$, and depth $=-2,605.6 \mathrm{~m}$, which corresponds to $\mathrm{x}=62.7 \mathrm{~m}, \mathrm{y}=39.0 \mathrm{~m}$, and $\mathrm{z}=75.6 \mathrm{~m}$ in the numerical model. Based on the inverse analysis from Yamada et al. (2005), information on the fault and the auxiliary planes corresponding to this event were determined as $59.8^{\circ} / 75.1^{\circ} /-91.3^{\circ}$ and $245^{\circ} / 15^{\circ} /-85^{\circ}$ for the strike/dip/rake, respectively. The derived parameters indicate that this event was a normal fault seismic event, which corresponded well with the vertical stress concentration near the stope mining front. Based on these data, source parameters for the moment tensor point source model and the finite kinematic source model can be determined to represent this seismic event.

In kinematic source modelling, a fault plane can be divided to a series of sub-faults and each sub-fault is considered as a point source (Doornbos 1982; Boore 2003; Miyake et al. 2003). According to the type of rupture model (i.e. unilateral or bilateral rupture) and the rupture velocity (i.e. sub-shear or super-shear), the space-time distribution of each sub-fault slip can be estimated. Source parameters, such as nucleation point position, rupture area, rupture velocity, rise time, and time function need to be determined. The length and width of the rupture area and the number and size of the sub-faults can be estimated from the intensity of the seismic event according to some empirical relations given in literatures (i.e. Wells \& Coppersmith 1994; Haddon 1996; Mai \& Beroza 2000; Beresnev \& Atkinson 2002; Dowrick \& Rhoades 2004). 
In this study, the kinematic seismic source parameters were determined through a comparison of the recorded and the synthetic seismograms using the trial-and-error method. After conducting a large number of iterative simulations, one possible schematic representation of the potential fault plane and the source rupture model was derived, which is shown in Figure 5 . The fault plane (strike/dip/rake $\left.\phi_{s} / \delta_{d} / \gamma_{r}=59.8^{\circ} / 75.1^{\circ} /-91.3^{\circ}\right)$ and the hypocentre $((x, y, z)=(62.7,39.0,75.6) \mathrm{m})$ were derived by Yamada et al. (2005) in their inverse analysis, which are shown in Figure 5(a). The point source model is shown in Figure 5(b) and the kinematic rupture source model is illustrated in Figure 5(c) and (d). The derived fault area was considered as a square-shaped fault plane $\left(21 \times 21 \mathrm{~m}^{2}\right)$ (Yamada et al. (2005)), which was divided into $7 \times 7=49$ sub-faults. The centre of the fault plane corresponded to the hypocentre of seismic event \#1. For each sub-fault, a moment tensor source model was used and the sum of the seismic moments for the 49 sub-faults was constrained by the seismic moment of the event that had a moment magnitude of $M_{w}=1.4$ (with a seismic moment $M_{0}$ of $1.6 \times 10^{18}$ dyne.cm). Based on the results by Yamada et al. (2005), the rupture velocity was estimated as $2,500 \mathrm{~m} / \mathrm{s}$ (or $65 \%$ shear wave velocity). The time interval between each sub-fault was $0.0012 \mathrm{~s}$ in the model, estimated based on the rupture velocity of the fault.

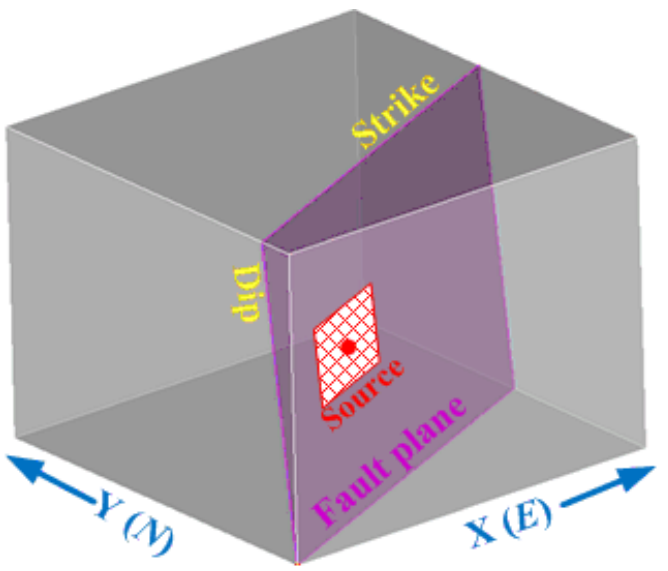

(a)

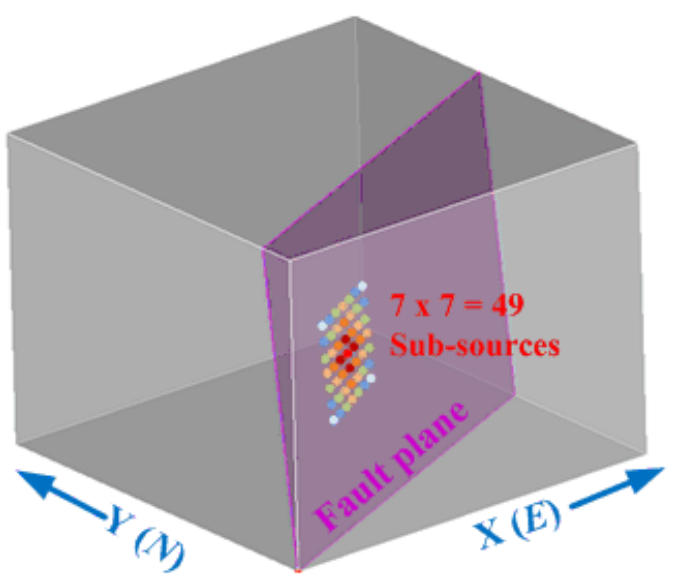

(c)

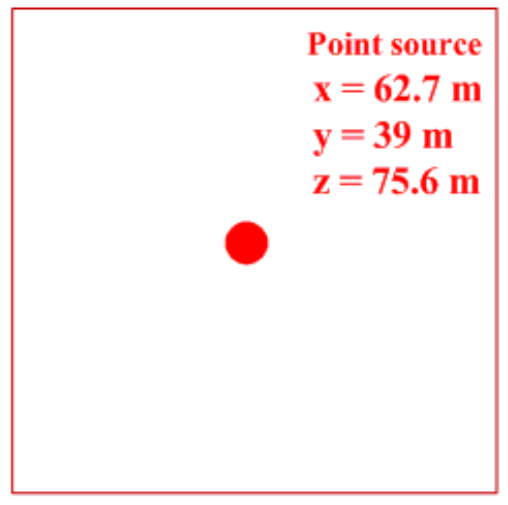

(b)

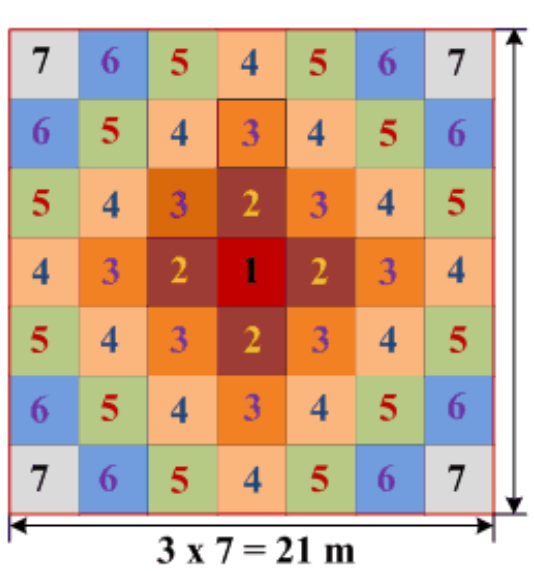

(d)

$$
\begin{aligned}
& M_{\mathrm{w}}=1.4 \\
& M_{0}=1.56 \times 10^{18} \text { dyne } \cdot \mathrm{cm} \\
& M_{x x}=6.11 \times 10^{17} \text { dyne } \cdot \mathrm{cm} \\
& M_{y y}=1.67 \times 10^{17} \text { dyne } \cdot \mathrm{cm} \\
& M_{z z}=-7.78 \times 10^{17} \text { dyne } \cdot \mathrm{cm} \\
& M_{x y}=-3.21 \times 10^{17} \text { dyne } \cdot \mathrm{cm} \\
& M_{x z}=-1.17 \times 10^{18} \text { dyne } \cdot \mathrm{cm} \\
& M_{y z}=6.91 \times 10^{17} \text { dyne } \cdot \mathrm{cm}
\end{aligned}
$$

$$
\begin{aligned}
& \sum_{1}^{49} M_{0 \text { each }}=M_{0} \\
& \text { For each sub-fault: } \\
& M_{x x}=1.25 \times 10^{16} \text { dyne } \cdot \mathrm{cm} \\
& M_{y y}=3.41 \times 10^{15} \text { dyne } \cdot \mathrm{cm} \\
& M_{z z}=-1.58 \times 10^{16} \text { dyne } \cdot \mathrm{cm} \\
& M_{x y}=-6.56 \times 10^{16} \text { dyne } \cdot \mathrm{cm} \\
& M_{x z}=-2.39 \times 10^{16} \text { dyne } \cdot \mathrm{cm} \\
& M_{y z}=1.41 \times 10^{16} \text { dyne } \cdot \mathrm{cm}
\end{aligned}
$$

Figure 5 (a) Derived fault plane and the seismic source hypocentre; (b) The point source model. The kinematic rupture source model is shown in (c) and (d)

\section{$4 \quad$ Modelling results and discussion}

\subsection{Source radiation evolution}

The focus of this study is to understand the influence of different source models on the seismic response in the near field. Source radiation evolutions of different source models are firstly examined by visual inspection of the vertical velocity component contours in the area near the seismic source. As can be seen from Figure 6 , 
contours of the vertical velocity component $\left(V_{z}\right)$ are used to visualise seismic wave evolution at different times. Figure 6(a) and (d) show the wave radiation patterns for the moment tensor point source model and the kinematic rupture source model, respectively. It is seen that the wave radiation patterns are different for the two source models. The kinematic rupture source model seems to represent the characteristics of fault plane slip better than the point source model when the near field wave patterns are considered.

Figure(b) and (c) present the $V_{z}$ contours in the fault plane. In the point source modelling results, the maximum $V_{z}$ value (about $180 \mathrm{~m} / \mathrm{s}$ ) is observed at $t=0.004 \mathrm{~s}$, which could not be shown in Figure $6(\mathrm{~b})$ for the given velocity range of -3 to $3 \mathrm{~m} / \mathrm{s}$. As the waves propagate, the $V_{z}$ values decrease quickly, which suggests that all seismic energy is released when the point source is triggered. On the other hand, the kinematic characteristic of the fault plane is observed when the kinematic rupture source model is used (Figure $6(\mathrm{c})$ ). In this case, the maximum $V_{z}$ (about $30 \mathrm{~m} / \mathrm{s}$ ) is obtained at $t=0.008 \mathrm{~s}$ when all 49 sub-faults are triggered or activated at $t=0.0072 \mathrm{~s}$, which could not be shown in Figure 6(c) for the given velocity range $(-3$ to $3 \mathrm{~m} / \mathrm{s})$. The maximum $V_{z}$ of the kinematic rupture source model is smaller. This makes sense because the activation of a fault slip cannot cease instantly and there is a process of fault rupture propagation. Hence, the kinematic source rupture model is preferred for near field source representation compared with the point source model. This will be further discussed using seismograms in Section 4.3.
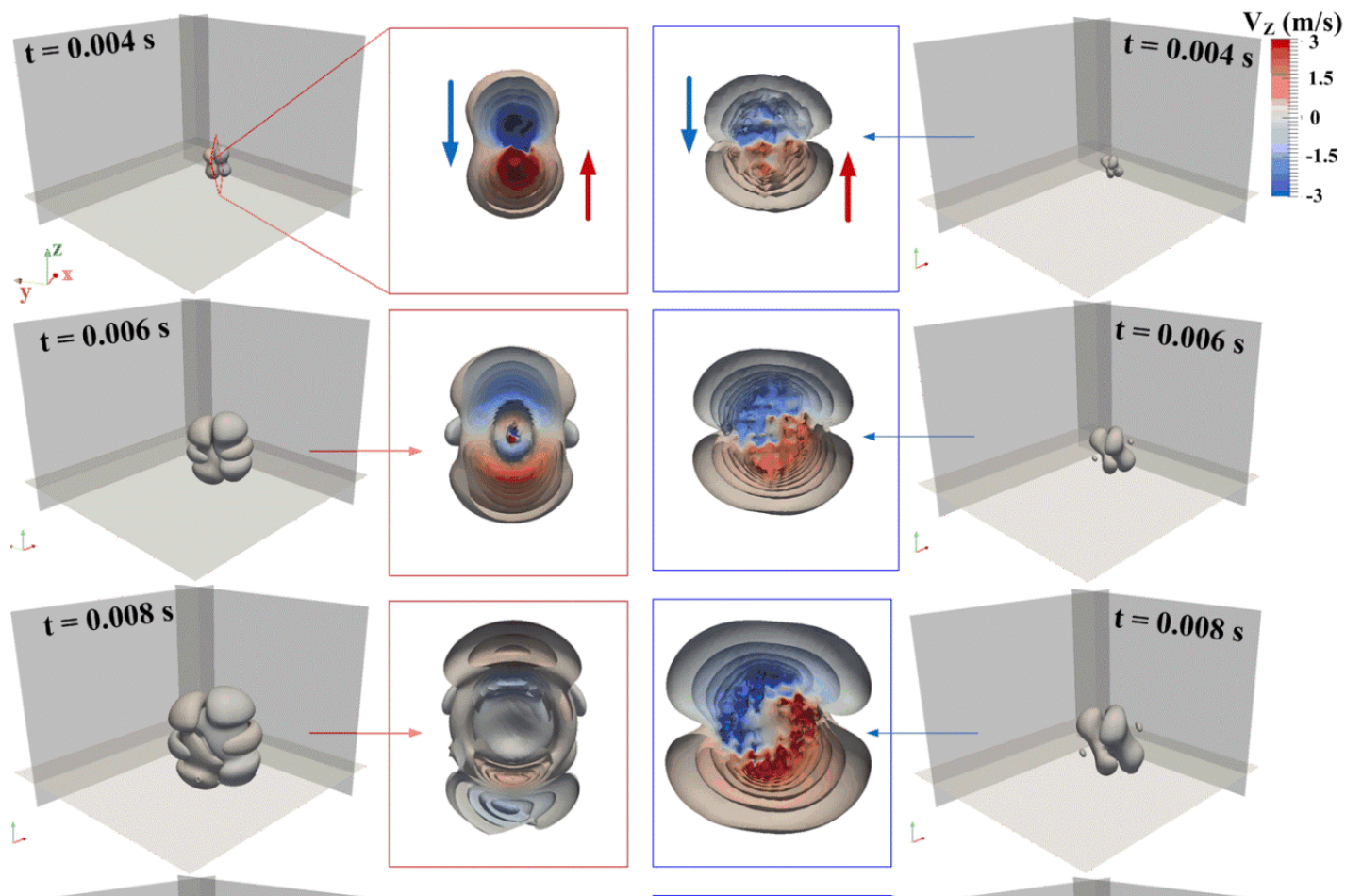

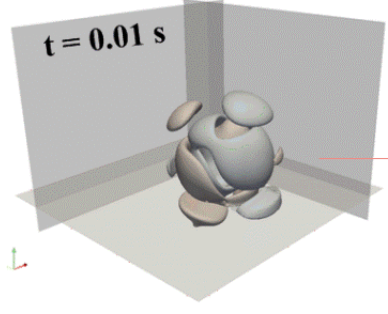

(a)

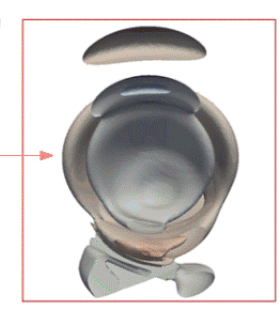

(b)

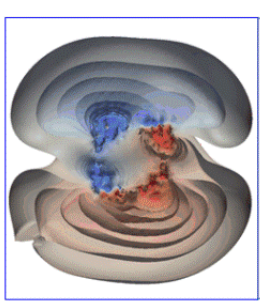

(c)

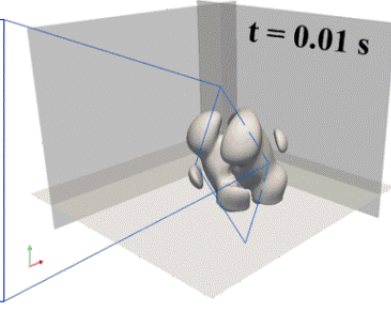

(d)

Figure 6 Contours of the vertical velocity component $\left(V_{z}\right)$ at four propagation times $(t=0.004,0.006$, 0.008 , and $0.01 \mathrm{~s}$ ) for the moment tensor point source model (a); and the kinematic non-point source model (d). The $V_{z}$ contours along the fault plane are shown in (b) and (c) for the point source and non-point models, respectively. It should be noted that the velocity values at some locations are much higher than $3 \mathrm{~m} / \mathrm{s}$ but only those ranged from -3 to $3 \mathrm{~m} / \mathrm{s}$ are plotted 


\subsection{Influence of haulage tunnel and mined-out area on wavefield}

The geological settings are relatively simple in this model, which provides a good case for studying the influence of the haulage tunnel and the mined-out areas on wave propagation. Isosurfaces of the vertical velocity component are used to examine the wavefield.

Figure 7 presents the $V_{z}$ isosurfaces at five propagation times for the point and the non-point (kinematic rupture) source models. Different $V_{z}$ values are selected to generate the isosurfaces to compare the results from the two source models. At early stages of wave propagation ( $t=0.06 \mathrm{~s}$ and $t=0.01 \mathrm{~s})$, small but detectable differences in the wavefields are observed. The kinematic rupture source model can represent the fault area better in the near field source representation. At later stages of wave propagation, the wavefields have similar patterns for the two source models. Again, the wavefield difference in the early stage of wave propagation around the source area could be expected because different seismic source models are used.

In addition, the influence of the haulage tunnel and the mined-out areas on the wavefields can be seen from the results of both source models, as indicated by the red dash line circled areas in Figure 7 at $t=0.03 \mathrm{~s}$ and $t=0.04 \mathrm{~s}$. Complex wavefields are observed around the areas of the haulage tunnel and the mined-out stope. The complex wavefields can only be captured when detailed geometries of the tunnel and stopes are properly considered in numerical modelling.

A homogenous model (i.e., rock mass is assumed uniform in the whole model and it uses the property of quartzite) was considered to further examine the influence of the haulage tunnel and mined-out areas on seismic wave propagation. $V_{z}$ contours of the kinematic rupture source model at $t=0.04 \mathrm{~s}$ for the homogenous model and the heterogeneous model (which includes different rock domains, haulage tunnel, and mined-out areas) are dissected into different $V_{z}$ values and are shown in Figure 8.

It is seen that large wave velocities are generated around the haulage tunnel and the mined-out area in the heterogeneous model when compared with the results of the homogeneous model (Figure 8(a)), indicating that mine structures can alter ground motions. The maximum vertical velocity is $0.035 \mathrm{~m} / \mathrm{s}$ in the homogenous model; however, in the heterogeneous model, the maximum vertical velocity is $V_{z}=0.1 \mathrm{~m} / \mathrm{s}$ and it appears on the top of the haulage tunnel and the mined-out area in the southeast side of the gold reef (Figure $8(b))$. Only a certain part of the haulage tunnel is subjected to this strong ground motion (blue area in Figure 8(b)). Although there are many other factors that cause rockburst damage (Cai et al. 2012; Kaiser \& Cai 2012), the pattern of elevation ground motions suggests that these areas may be more prone to failure if all other factors are equal. Furthermore, relatively large $V_{z}$ values $(0.025$ to $0.05 \mathrm{~m} / \mathrm{s})$ are observed around the top of tunnel and the mined-out areas Figure $8(\mathrm{~b})$. Moreover, the wavefield is affected by the gold reef and the two rock domains (basalt and quartzite). For example, the influence of different rock types on the velocity field can be clearly seen when smaller velocity range values $(-0.01$ and $0.01 \mathrm{~m} / \mathrm{s}$ ) are selected to plot the results.

As shown in the bottom plots of Figure $8(a)$ and (b), a simple velocity field is observed in the homogeneous model while a complex and elevated velocity field can be seen in the heterogeneous model. Tunnels and mined-out areas as well as geology can influence the wavefield and an accurate investigation of the problem requires 3D wave propagation modelling such as the case study presented in this paper. 


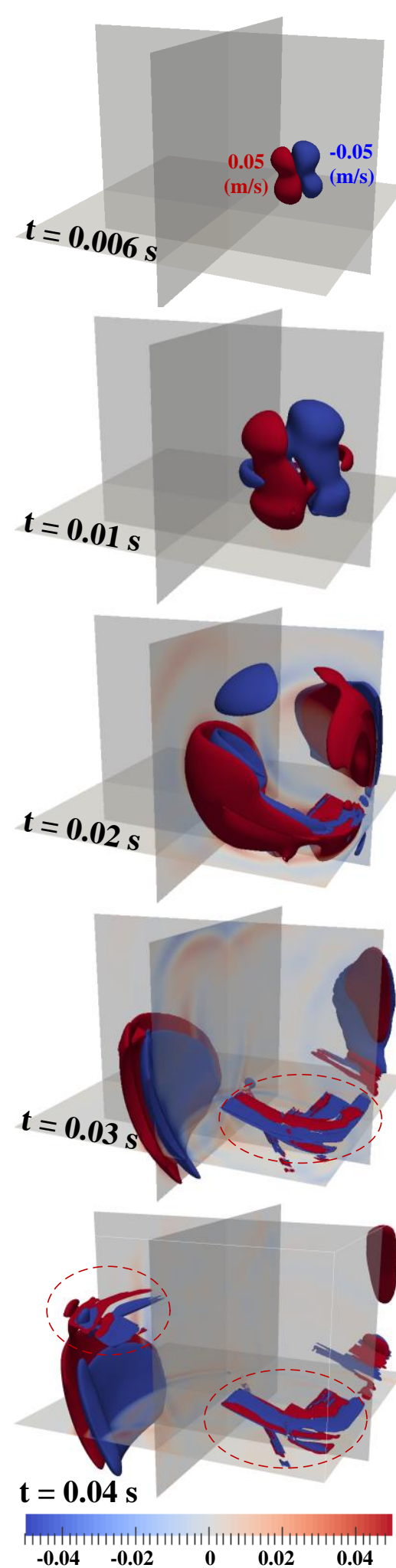

(a)

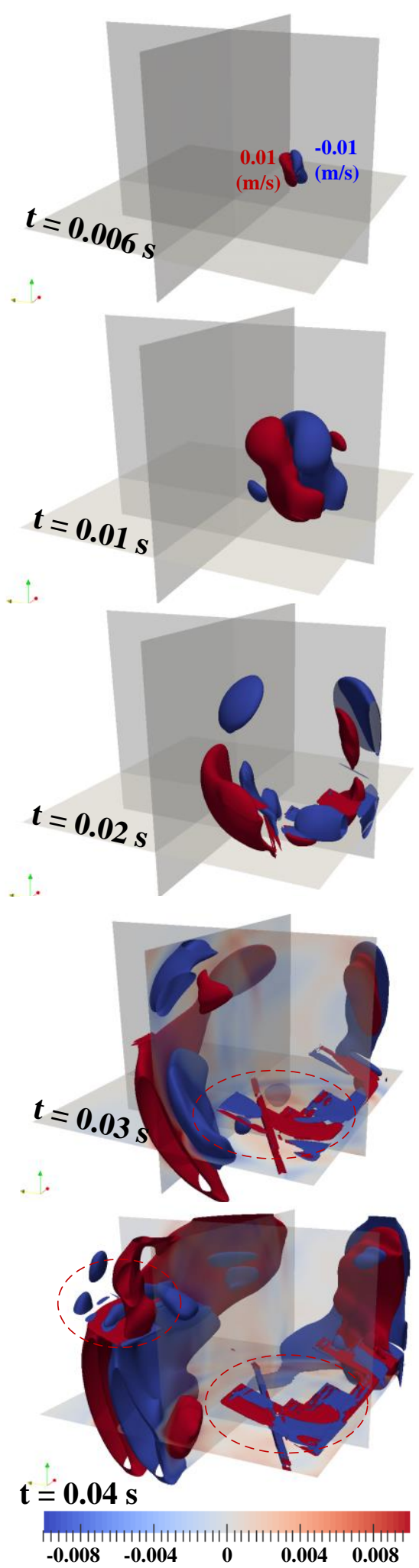

(b)

Figure 7 Isosurfaces of the vertical velocity component $\left(\mathrm{V}_{\mathrm{z}}, \mathrm{m} / \mathrm{s}\right)$ at five propagation times $(\mathrm{t}=0.006$, $0.01,0.02,0.03,0.04 \mathrm{~s})$ for the moment tensor point source model (a); and the kinematic non-point source model (b). $V_{z}$ isosurfaces are plotted in ranges of -0.05 to $0.05 \mathrm{~m} / \mathrm{s}$ (a); and -0.01 to $0.01 \mathrm{~m} / \mathrm{s}$ (b) for the point and non-point source models, respectively. Red and blue indicate upward and downward velocities, respectively 

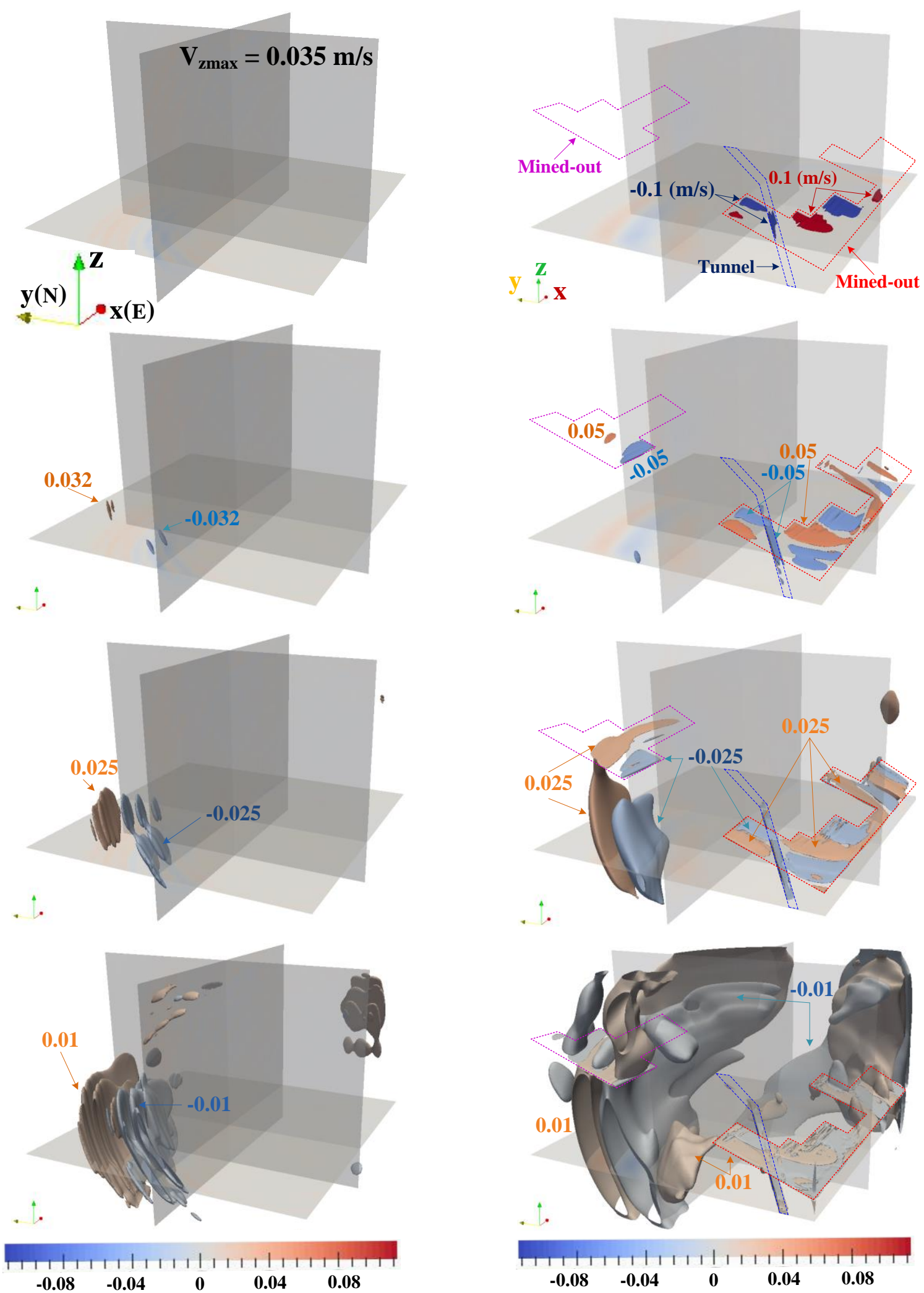

(a)

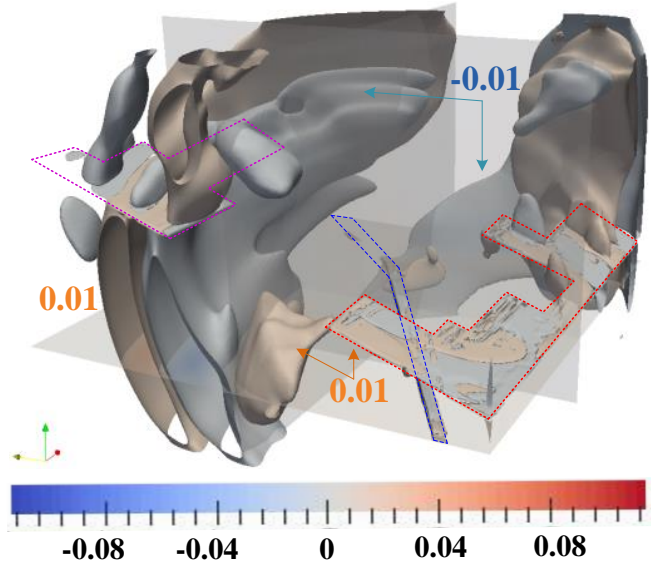

(b)

Figure 8 Anatomy of $V_{z}(m / s)$ contours for the kinematic rupture source model at $t=0.04 \mathrm{~s}$ for the homogenous model (a); and the heterogeneous model (b). Various $V_{z}$ values are selected to show the influence of the tunnel and the mined-out areas on velocity distribution to better illustrate the $\mathrm{V}_{\mathrm{z}}$ distribution 


\subsection{Comparison between the recorded waveforms and the synthetic seismograms}

Figure 9 presents the field recorded and the synthetic seismograms, which are denoted by the black and red lines, respectively, at six stations of the horizontal velocity component in the $x$ direction $\left(V_{x}\right)$. Velocity components of $V_{y}$ and $V_{z}$ are not available from the literature and will not be compared here. For receivers 1,2 , and 9, field data is also not available. Some receivers such as St.3, St.4, and St.5 are located very close to the seismic source, with a distance around 40 to $50 \mathrm{~m}$ from the receivers to the lower edge of the kinematic source. The modelling results reproduce only some portions of the seismograms. Many high-frequency components are observed in the recorded seismograms but are not captured in the numerical modelling results. Despite this, the maximum amplitude (except St.3) and the initial portion of the seismograms are captured properly.

For receivers St.6, St.7, and St.8 located in the far field (with a source centre-receiver distance from 105 to $130 \mathrm{~m}$ ), the simulated seismograms agree well with the recorded seismograms (Figure 9), especially in the second portion of the seismograms. Some high-frequency components are visible in the simulated seismograms, but to a smaller extent compared with the field data. The amplitudes of the simulated seismograms in the first portion of the seismograms are slightly higher than the amplitudes in the recorded seismograms. This may be caused by seismic wave attenuation, which was not considered in the modelling due to computation time constraints. High-frequency wave components can be attenuated quickly as waves propagate at distances far away from the source area and a relatively stable wave frequency (e.g. corner frequency) may dominate in the far field seismograms. It is suggested to check the influence of attenuation on the result in future studies. Despite this limitation, the synthetic seismograms are comparable to the field waveforms. The modelling result indicates that high-frequency wave components could influence ground motion.

A comparison between the recorded and the synthetic $V_{x}$ seismograms from the point and non-point source models at two stations (St.4 and St.7) are shown in Figure 10. Black, red and blue lines stand for the recorded seismograms and the synthetic seismograms from the point and the non-point source models, respectively. The seismograms from the point source model do not match well with the recorded waveforms for both St.4 and St.7. However, the synthetic seismograms from the non-point source model agree with the recorded waveforms well, especially for the first portion of St.4 and the second portion of St.7. This further suggests that the non-point source model could be a better source representation than the point source model when the near-source wavefield is of interest.

It can be seen from Figure 10 that there are some discrepancies between the simulated and the recorded waveforms in some portions of the seismograms. For instance, although negligible, there is a shift of the first arrival P-wave at St. 4; there is also a misfit in the seismogram for the propagation time between 0.025 and $0.05 \mathrm{~s}$. The misfit is relatively large in the first part of the seismogram at St.7, although the simulated waveform resembles the recorded one well (from $t=0.02$ to $0.035 \mathrm{~s}$ ). This is not surprising because we are dealing with very complex geological, geometrical, and geotechnical conditions in a deep underground mine. In addition, the seismic response in the near field is less understood. Even though the recorded seismograms cannot be reproduced exactly, the agreement between the results from the non-point source model and the field data suggests that the adopted non-point source model captures the major wavefield response. Hence, non-point source models should be considered in numerical modelling when studying near field wave propagation in underground mines. 


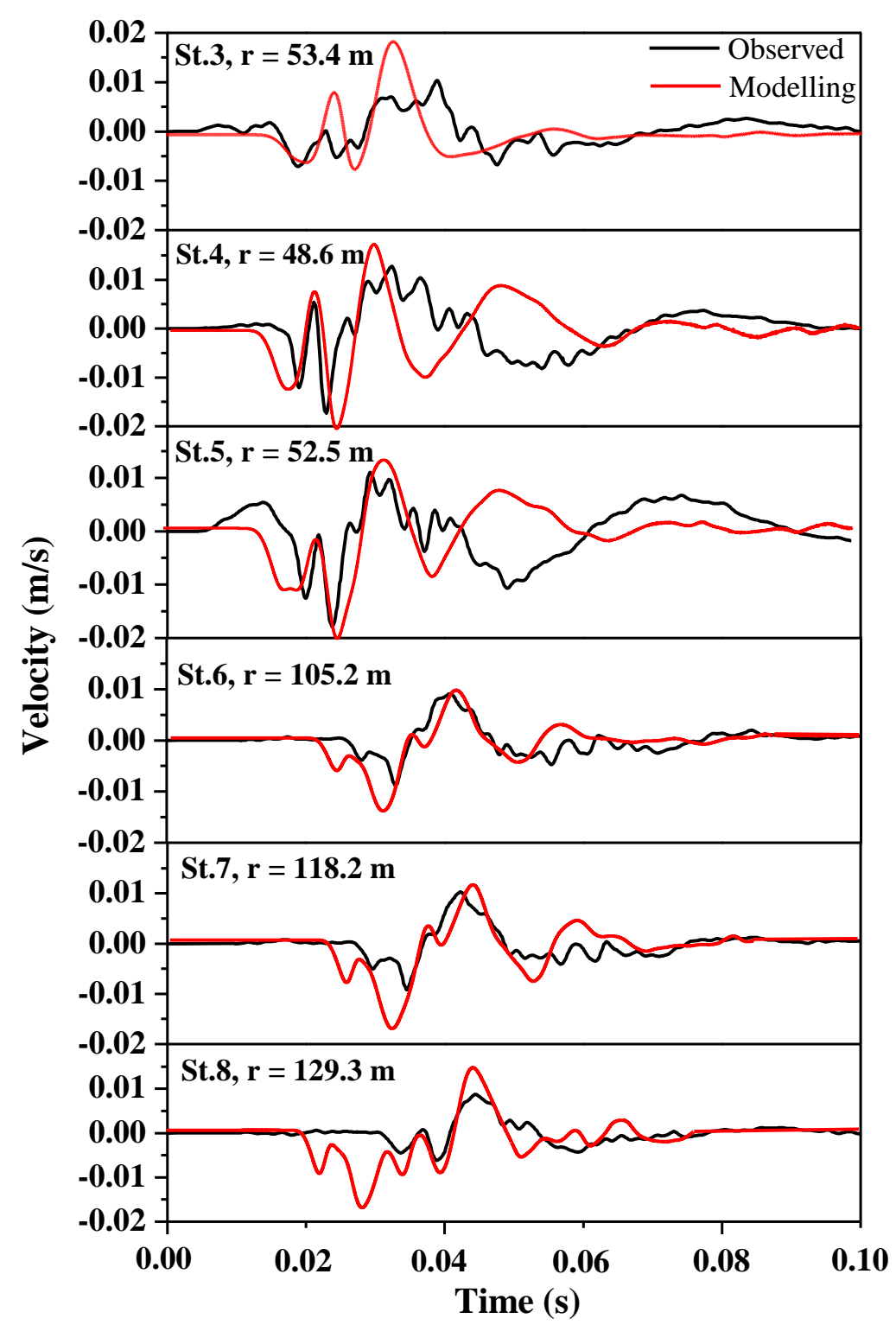

Figure 9 Field recorded (solid black lines) and synthetic (dashed red lines) seismograms of $V_{x}$ using the non-point seismic source model. ' $r$ ' denotes the source-receiver stations distance

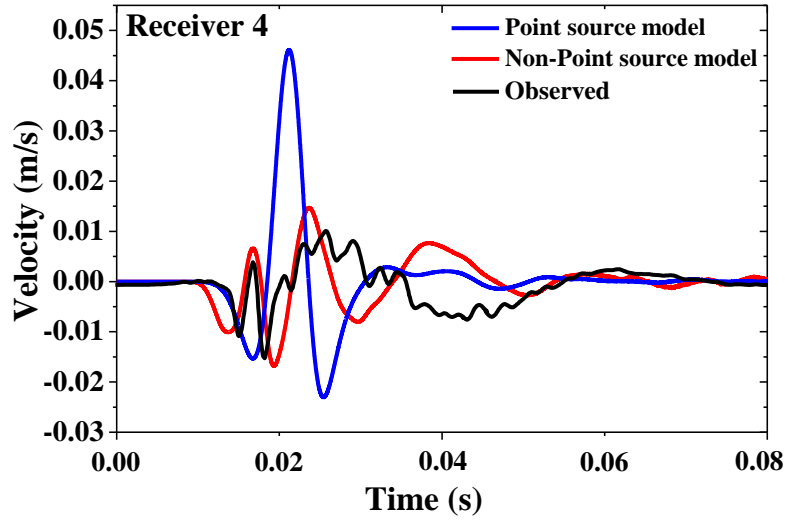

(a)

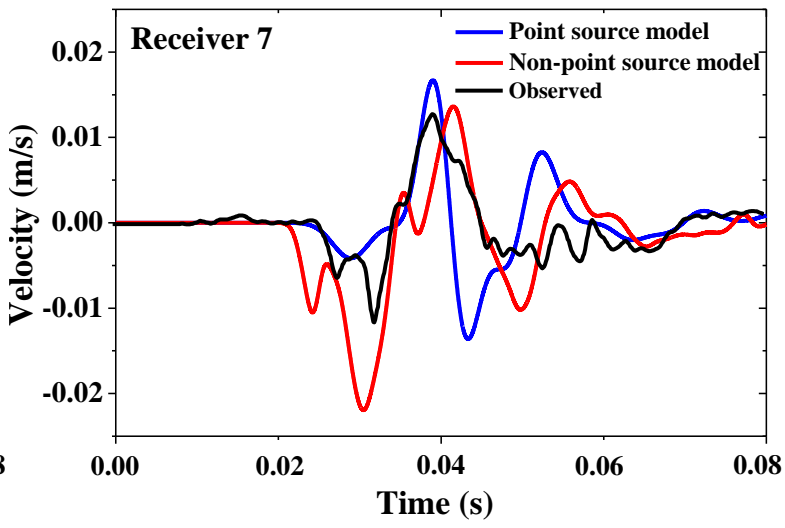

(b)

Figure 10 Recorded and synthetic seismograms of the horizontal velocity component $\left(\mathrm{V}_{\mathrm{x}}\right)$ at St.4 (a); and St.7 (b) for the point and non-point source models 


\section{Conclusion}

A case study of seismic wave propagation in a South African gold mine was conducted to demonstrate the applicability of SPECFEM3D for ground motion modelling in underground mines. Two source models, i.e. point moment tensor and kinematic rupture source models, were considered for near field seismic source representation. Through numerical tests using the trial-and-error method, the parameters for the non-point source model were determined and the obtained synthetic seismograms agree with the field observation data. The modelling results capture the influence of geology and excavation on ground motion. It is seen that the non-point source model could be a better representation of the fault slip seismic source than the point source model when near field seismic response is of interest. Another benefit from this case study is that techniques such as high-quality mesh generation, parallel computing using CPUs and GPUs, and post-processing have been acquired for wave propagation modelling using SPECFEM3D, which increases the confidence of using SPECFEM3D for realistic ground motion and wave propagation modelling in underground mines.

In many cases, rockbursts in tunnels are triggered by seismic events occurring not far away from the damage locations. Near field wavefield analysis should be conducted in such cases to obtain ground motion for dynamic stress increase assessment. Ground motion in the near field is complex and not well understood. As noted by Potvin and Wesseloo (2013), due to a lack of reliable near field data, traditional approaches to define ground motion in the near field may be inadequate and more or less oversimplified. It should be noted that the kinematic rupture source representation used in this study should be viewed as a high-level preliminary approximation. It describes only the kinematic features of a fault slip event and it does not consider the dynamic features of fault slip, such as constraint of in situ stress, stress drop, and fracturing mechanism. More studies are needed in this aspect, using more refined models that are quantitatively constrained by in situ stress and other properties from geophysical observations.

\section{Acknowledgement}

The authors acknowledge financial support provided by the Ontario Research Fund: SUMIT (ORF), Natural Sciences and Engineering Research Council of Canada: RGPIN/249620-2011 (NSERC), Vale, Rio Tinto, and Glencore. The authors thank the Computational Infrastructure for Geodynamics (CIG) for providing the open-source software package SPECFEM3D (www.geodynamics.org).

\section{References}

Beresnev, IA \& Atkinson, GM 2002, 'Source parameters of earthquakes in eastern and western North America based on finite-fault modeling', Bulletin of the Seismological Society of America, vol. 92, no. 2, pp. 695-710.

Boore, DM 2003, 'Simulation of ground motion using the stochastic method', Pure and Applied Geophysics, vol. 160, no. 3-4, pp. 635-676.

Cai, M, Kaiser, P \& Duff, D 2012, 'Rock support design in burst-prone ground utilizing an interactive design tool', Proceedings of the 46th US Rock Mechanics/Geomechanics Symposium, American Rock Mechanics Association, ARMA 12-599, Alexandria.

Cai, M \& Wang, X 2015, 'A non-uniform velocity model and FLAC/SPECFEM2D coupled numerical simulation of wave propagation in underground mines', Proceeding of the 13th ISRM International Congress of Rock Mechanics, International Society for Rock Mechanics, Lisbon, paper 275, $217 \mathrm{p}$.

Computational Infrastructure for Geodynamics 2012, SPECFEM2D User Manual, version 7.0, viewed 30 May 2017, http://geodynamics.org/cig/software/specfem2d/specfem2d-manual.pdf.

Computational Infrastructure for Geodynamics 2014, SPECFEM3D Cartesian User Manual, version 2.1, viewed 30 May 2017, http://geodynamics.org/cig/software/specfem3d/specfem3d-manual.pdf.

Doornbos, D 1982, 'Seismic moment tensors and kinematic source parameters', Geophysical Journal International, vol. 69, no. 1, pp. 235-251.

Dowrick, DJ \& Rhoades, DA 2004, 'Relations between earthquake magnitude and fault rupture dimensions: How regionally variable are they?', Bulletin of the Seismological Society of America, vol. 94, no. 3, pp. 776-788.

Haddon, R 1996, 'Use of empirical Green's functions, spectral ratios, and kinematic source models for simulating strong ground motion', Bulletin of the Seismological Society of America, vol. 86, no. 3, pp. 597-615.

Kaiser, P \& Cai, M 2012, 'Design of rock support system under rockburst condition', Journal of Rock Mechanics and Geotechnical Engineering, vol. 4, no. 3, pp. 215-227. 
Komatitsch, D, Barnes, C \& Tromp, J 2000, 'Simulation of anisotropic wave propagation based upon a spectral element method', Geophysics, vol. 65, no. 4, pp. 1251-1260.

Komatitsch, D \& Tromp, J 1999, 'Introduction to the spectral element method for three-dimensional seismic wave propagation', Geophysical Journal International, vol. 139, no. 3, pp. 806-822.

Kwiatek, G, Plenkers, K \& Dresen, G 2011, 'Source parameters of picoseismicity recorded at Mponeng deep gold mine, South Africa: implications for scaling relations', Bulletin of the Seismological Society of America, vol. 101, no. 6, pp. 2592-2608.

Mai, PM \& Beroza, GC 2000, 'Source scaling properties from finite-fault-rupture models', Bulletin of the Seismological Society of America, vol. 90, no. 3, pp. 604-615.

McGarr, A 1971, 'Violent deformation of rock near deep-level, tabular excavations-seismic events', Bulletin of the Seismological Society of America, vol. 61, no. 5, pp. 1453-1466.

McGarr, A 1994, 'Some comparisons between mining-induced and laboratory earthquakes', Pure and Applied Geophysics, vol. 142, no. 3-4, pp. 467-489.

McGarr, A, Spottiswoode, S \& Gay, N 1975, 'Relationship of mine tremors to induced stresses and to rock properties in the focal region', Bulletin of the Seismological Society of America, vol. 65, no. 4, pp. 981-993.

McGarr, A, Spottiswoode, S, Gay, N \& Ortlepp, W 1979, 'Observations relevant to seismic driving stress, stress drop, and efficiency', Journal of Geophysical Research: Solid Earth (1978-2012), vol. 84, no. B5, pp. 2,251-2,261.

Miyake, H, Iwata, T \& Irikura, K 2003, 'Source characterization for broadband ground-motion simulation: Kinematic heterogeneous source model and strong motion generation area', Bulletin of the Seismological Society of America, vol. 93, no. 6, pp. 2531-2,45.

Ogasawara, H \& The Research Group for Semi-controlled Earthquake-generation Experiments in South African Deep Gold Mines 2002, 'Review of semi-controlled earthquake generation experiments in South African deep gold mines', in H Ogasawara, T Yanagidani and M Ando (eds), Seismogenic Process Monitoring, A.A. Balkema, Rotterdam, pp. 119-150.

Potvin, Y \& Wesseloo, J 2013, 'Towards an understanding of dynamic demand on ground support', South African Institute of Mining and Metallurgy, vol. 113, no. 12, pp. 913-922.

Richardson, E \& Jordan, TH 2002, 'Seismicity in deep gold mines of South Africa: Implications for tectonic earthquakes', Bulletin of the Seismological Society of America, vol. 92, no. 5, pp. 1,766-1,782.

Spottiswoode, S \& McGarr, A 1975, 'Source parameters of tremors in a deep-level gold mine', Bulletin of the Seismological Society of America, vol. 65, no. 1, pp. 93-112.

Wang, X \& Cai, M 2014, 'Wave propagation simulation in underground mines by SPECFEM2D', in M Hudyma \& Y Potvin (eds), Proceedings of the Seventh International Conference on Deep and High Stress Mining, Australian Centre for Geomechanics, Perth, pp. 723-738.

Wang, X \& Cai, M 2015, 'Influence of wavelength-to-excavation span ratio on ground motion around deep underground excavations', Tunnelling and Underground Space Technology, vol. 49, pp. 438-453.

Wang, X \& Cai, M 2016, 'FLAC/SPECFEM2D coupled numerical simulation of wavefields near excavation boundaries in underground mines', Computers \& Geosciences, vol. 96, pp. 147-158.

Wells, DL \& Coppersmith, KJ 1994, 'New empirical relationships among magnitude, rupture length, rupture width, rupture area, and surface displacement', Bulletin of the Seismological Society of America, vol. 84, no. 4, pp. 974-1002.

Yamada, T, Mori, JJ, Ide, S, Abercrombie, RE, Kawakata, H, Nakatani, M, lio, Y \& Ogasawara, H 2007, 'Stress drops and radiated seismic energies of microearthquakes in a South African gold mine', Journal of Geophysical Research: Solid Earth (1978-2012), vol. 112, no. B03305.

Yamada, T, Mori, JJ, Ide, S, Kawakata, H, lio, Y \& Ogasawara, H 2005, 'Radiation efficiency and apparent stress of small earthquakes in a South African gold mine', Journal of Geophysical Research, vol. 110, no. B01305. 